\title{
The effects of smoke-free legislation on acute myocardial infarction: a systematic review and meta-analysis
}

Hualiang Lin ${ }^{1,2}$, Hongchun Wang ${ }^{3}$, Wei Wu ${ }^{1,2}$, Lingling Lang ${ }^{1,2}$, Qinzhou Wang ${ }^{4}$ and Linwei Tian ${ }^{5,6^{*}}$

\begin{abstract}
Background: Comprehensive smoke-free legislation has been implemented in many countries. The current study quantitatively examined the reduction in risk of acute myocardial infarction (MI) occurrence following the legislations and the relationship with the corresponding smoking prevalence decrease.

Methods: PubMed, EMBASE, and Google Scholar databases and bibliographies of relevant studies and reviews were searched for potential original studies published from January 1, 2004, through October 31, 2011. Meta-analysis was performed using a random effect model to estimate the overall effects of the smoking-free legislations. Meta-regression was used to investigate possible causes of heterogeneity in risk estimates.

Results: A total of 18 eligible studies with 44 estimates of effect size were used in this study. Meta-analysis produced a pooled estimate of the relative risk of 0.87 (95\% confidence interval (Cl): 0.84 to 0.91 ). There was significant heterogeneity in the risk estimates (overall $I^{2}=96.03 \%, p<0.001$ ). In meta-regression analysis, studies with greater smoking prevalence decrease produced larger relative risk (adjusted coefficient $-0.027,95 \% \mathrm{Cl}:-0.049$ to $-0.006, \mathrm{p}=0.014$ ).
\end{abstract}

Conclusion: Smoke-free legislations in public and work places were associated with significant reduction in acute MI risk, which might be partly attributable to reduced smoking prevalence.

Keywords: Smoke-free legislation, Acute myocardial infarction, Systematic review, Meta-analysis, Random effect

\section{Background}

Tobacco smoking is projected to kill about one billion people worldwide in the 21st century [1]. The harmful effects of smoking are not only confined to active tobacco consumers, but also for those exposed to environmental tobacco smoke (ETS) [2], which is listed as the third leading cause of preventable poor health and premature deaths in the developed world [3]. According to the US Surgeon General's report, tobacco smoking is a major population risk factor for coronary heart disease, the leading cause of deaths in the US [4]. Including acute myocardial infarction (MI), coronary heart disease has remained the second leading cause of deaths over the past three decades [4,5]. The harmful health effects of smoking has prompted

\footnotetext{
* Correspondence: linweit@cuhk.edu.hk

${ }^{5}$ The Jockey Club School of Public Health and Primary Care, The Chinese University of Hong Kong, Hong Kong, China

${ }^{6}$ Shenzhen Municipal Key Laboratory for Health Risk Analysis, Shenzhen Research Institute of the Chinese University of Hong Kong, Shenzhen, China Full list of author information is available at the end of the article
}

many countries to enacted various smoking regulations in order to directly decrease exposure to environmental tobacco smoke and indirectly reduce active smoking, in hope to prevent and reduce smoking-related morbidity and mortality such as acute MI [6,7]. These smoking bans usually prohibited smoking activity in public and working places, such as restaurants, workplaces, and bars, although differnce existed among countries and cities [8]. A growing body of evidence has suggested that the rate of acute myocardial infarction significantly decreased after the introduction of the smoking ban regulations, usually within a short time period. However, the results published so far showed a large variation of the effect size, ranging from $5 \%$ to $70 \%$ [9]. On the other hand, the relationship of this reduction with the corresponding smoking prevalence change remained unknown. This study performed a systematic literature review and meta-analysis with the aim to estimate the overall effect size of smoke-free legislations on the risk of acute $\mathrm{MI}$ in the general population, and to

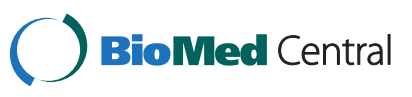


investigate the relationship between reduction in smoking prevalence and the acute MI rate change after the smoking-free legislations.

\section{Methods}

The literature search was conducted to find potential studies published from January 1, 2004, through October 31, 2011. We used the MEDLINE, EMBASE, and Google Scholar database without restrictions and we included articles that were ahead of publications. The following keywords were used in the literature searching: "smoking ban" and "heart" or "myocardial infarct". Moreover, we searched for the keywords in headers and abstracts and also performed a manual search of references cited in the selected articles and published reviews to look for any additional relevant studies. A total of 19 studies were identified, of which, 18 had been published in peer-reviewed journals and 1 had not. The latter study did not provide enough information for us to calculate relative risk and confidence interval, was thus not included in the meta-analysis.

Two individual studies included the city of Pueblo, Colorado: the first was on the effects for the first 18 months after the law being implemented [10] and the second was after 36 months [11]. And two studies reported that of the City of Graubuenden, Switzerland. One was one year after the smoking ban and the other one was two years after the regulation [12,13]. Data of Piedmont, Italy were used as part of one study, which was for the effect of 2 months after the law went into effect [14] and another study examined the effect of the smoking ban in Piedmont after 6 months of the implementation [15]. These studies were initially treated as independent observations in this study, although there was some overlaps in the baseline information. And in the sensitivity analysis, we only included the more recent studies for these cities in order to check the robustness of the result estimation. Information of New York was also included in two studies: one including the residents aged 35 years and over [16], the second including those of 45 years and above [17], only the former one was included in this analysis as it included the information of the latter one. One study [14] reported results from four Italian regions, one of which had already been reported individually [15]; the results for the other three regions were used separately into the meta-analysis.

Some studies reported separate relative risks for different age subgroups and sexes, these estimates were entered separately into the meta-analysis. The meta-analysis was therefore based on a total of 44 estimates of relative risk obtained from 18 individual studies.

When population data were not provided in the studies, they were obtained from the relevant country's census records. If the smoking prevalence information was not available in the study, the information was extracted from various sources. For example, the studies in the
USA, data were obtained from a report by American Lung Association [18]. And information of Toronto, Ontario Canada was obtained from [19], England from [20], Italy from [21], Christchurch, New Zealand from [22], Graubuenden, Switzerland from [23,24].

All analyses were performed using $\mathrm{R}$ software. As the studies were conducted in different countries and circumstances, we utilized a random-effect meta-analysis which allowed for non-random variability in effect estimates between the studies. A forest plot was produced to illustrate the contributions of each individual study in terms of their estimated effect size and the $95 \%$ confidence interval (CI). To examine potential publication bias, we plotted the standard errors (SEs) of the studies against the corresponding effect sizes. We assessed the possibility of publication bias by visually measuring the asymmetry of the funnel plot. A funnel plot could allow for widening 95\% $\mathrm{CI}$ lines with decreasing study size. If there was no significant bias, $95 \%$ of the studies would lie within these lines and, in the absence of small study bias, the plotted results should be symmetrical. We also used the Egger's linear regression method to statistically examine the symmetry. Meta-regression analysis was further conducted to examine whether the estimate of relative risk (RR) was associated with such factors as population size, study location (U.S. or non-U.S.), publication year and smoking prevalence decrease.

\section{Results}

This systematic review identified 18 eligible studies (9 conducted in US, 3 in Italy, 2 in Canada, 2 in Switzerland, 1 in Great Britain and 1 in New Zealand). All of the studies were based on acute MI hospitalization except that three studies used acute MI mortality data $[17,25,26]$.

All of the studies included a pre- and post- comparison of the acute MI hospitalization or mortality rate. Eleven also included a geographical comparison area where legislation had not yet been implemented [3,7,11,13,17,25-29]. These studies were all ecologic in the study design, and they varied widely in population size (ranging from 9,100 to more than 15 million), and in the duration of post-ban observation (from 2 to 36 months, with only 3 studies reporting results of within 12 months [14,15,28]).

As shown in Figure 1, the overall relative risk of acute MI before and after smoking-free legislations was 0.87 (95\% CI: 0.84-0.91), suggesting that the smoking-free legislations might have reduced acute MI occurrence by $13 \%$ on average. The study in New York observed an $8 \%$ reduction in hospitalization for acute myocardial infarction [16]. The authors estimated that the decline would have been $19 \%$ if there had been no prior local smoking restrictions. When we re-ran the analysis inputting a 19\% reduction rather than $8 \%$, the pooled estimate remained as $87 \%$ (95\% CI: $83 \%$ to $90 \%)$. 


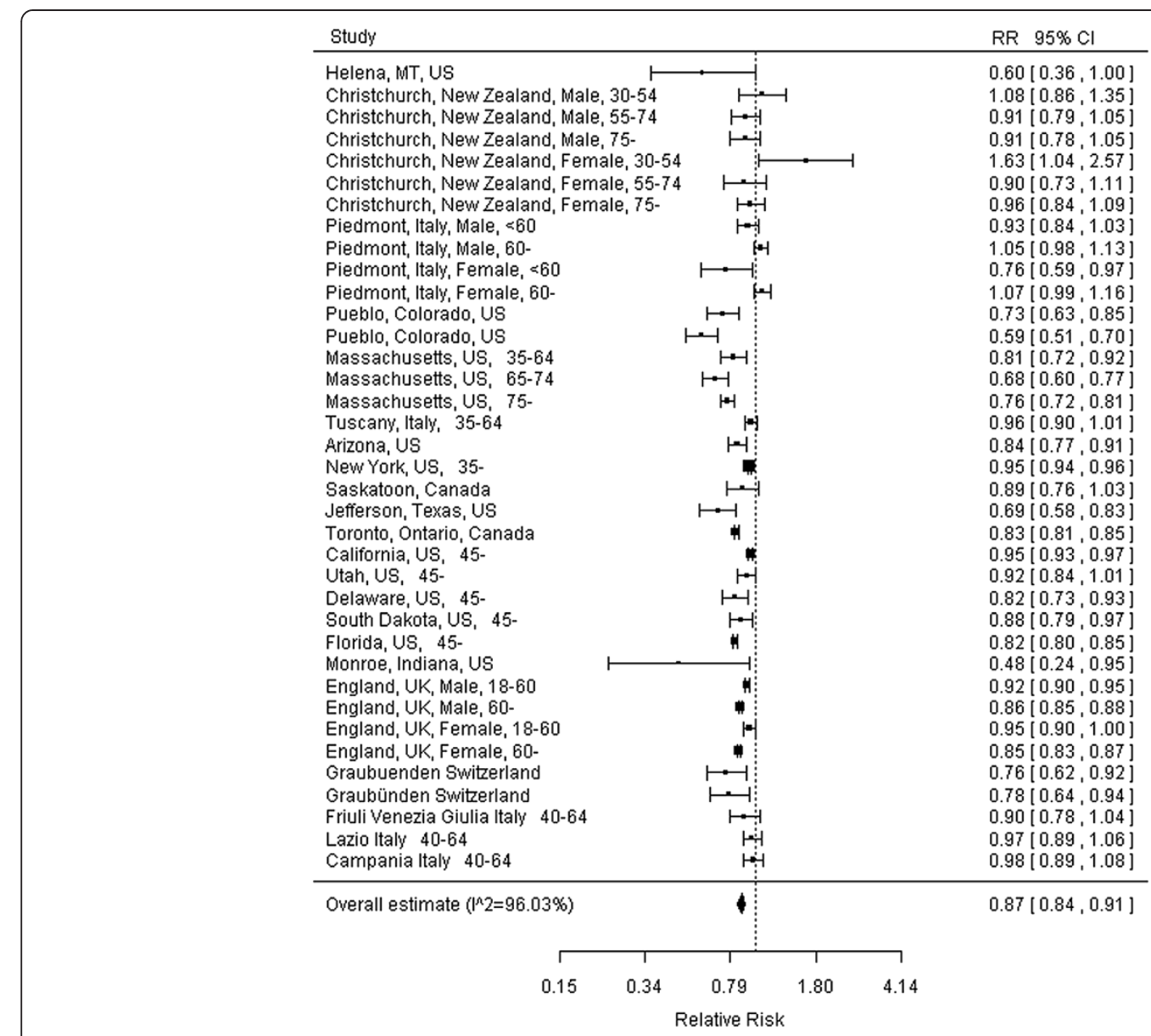

Figure 1 Forest plot of random effects meta-analysis of studies examining the effect of smoke-free legislation on acute myocardial infarction.

The overall $\mathrm{I}^{2}$ was $96.03 \%$, suggesting significant heterogeneity in the risk estimate in different areas $(p<0.001)$. The publication bias of the studies was examined by analyzing the funnel plot and Egger's regression test. As shown in Figure 2, the funnel plot appeared asymmetrical, and Egger's regression test suggested significant asymmetry (bias coefficient $=4.05, \mathrm{p}=0.0003$ ), indicating either publication bias or heterogeneity that cannot be simply explained by a random-effect meta-analysis.

In the sensitivity analysis, we excluded the studies with acute MI mortality as the outcome, the result estimate did not change appreciably ( $R R=0.89,95 \%$ CI: 0.85-0.93). When we included only the more recent studies for the same city in the meta-analysis, the effect remained similar ( $R R=0.84,95 \%$ CI: 0.84-0.92).

Further meta-regression analysis showed that the heterogeneity was partially explained by the study location and smoking prevalence rate change. In the univariate meta-regression analysis, study location (US vs. non-US, $\mathrm{p}=0.001)$ and smoking prevalence rate decrease $(\mathrm{p}=0.028)$ were significantly associated with estimated effect size (Table 1), and they remained significant predictors after adjustment for other study covariates in the multivariate analysis. There was a dose gradient that the higher the smoking prevalence decreases following the implementation of the smoking-free legislations, the greater the reduction in acute myocardial infarction occurrence (Figure 3).

\section{Discussion}

Since 2004, when the first report of a significant drop in acute MI rate related to the smoking ban in public and work places was published for the town of Helena, Montana [28], there has been an increasing number of demonstrations of this topic in various countries. The current study provided an up to date meta-analysis of the existing literatures on the effectiveness of smoking-free legislation on the risk of acute MI. Similar to the pooled estimates published in previous meta-analyses [30,31], this study of 18 studies (44 estimates) indicated a significant reduction of acute MI rate after the implementation of smoking bans in public and work places. To our knowledge, our study was the first to examine the association between the acute MI reduction and the corresponding smoking 


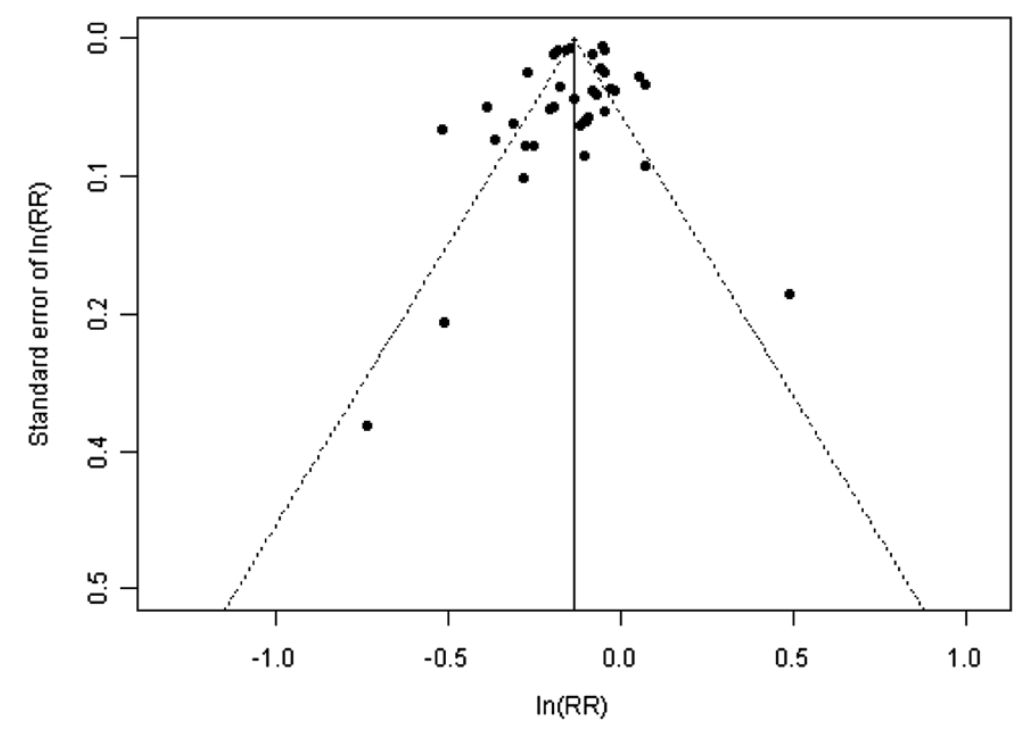

Figure 2 Funnel plot to illustrate possible small study bias among studies examining the effect of smoke-free legislation on acute myocardial infarction.

prevalence decrease, which provided further evidence of the association of environmental tobacco smoke with acute MI.

The findings from this meta-analysis indicated that the smoking-free legislations were associated with a reduced risk of acute MI in general population. Overall, the risk of acute MI decreased by $13 \%$, a moderate effect size compared with previous estimates of a $27 \%$ decrease by Dinno [32], an updated $19 \%$ reduction by Glantz [30] and $17 \%$ by two other studies [31,33]. However, our estimate was consistent with a $15 \%$ drop by one study [33]. And this was supported by Pechacek and Babb, which estimated $18 \%$ to $19 \%$ as the maximum impact that could be expected to be associated with smoking ban [34]. Some studies reported separate estimates for different subpopulations, only those with significant reductions were included by previous meta-analyses, which might be one reason for the relatively higher estimate by previous meta-analyses.
We noticed that the results published so far showed a large variation: studies with smaller population in the United States [10,11,28,35] usually reported larger reductions ranging from $27 \%$ to $40 \%$, while larger studies usually reported relative modest reductions: $5 \%$ in New Zealand [36], 8\% in New York [16], 13\% in four Italian regions [14], and 13\% in Switzerland [12]. At the same time, some subgroup estimates did not find significant reduction (for example, among people aged 60 years old and above in Piemont, Italy [15], population aged 30-54 years old in Christchurch, New Zealand [36]). The discrepancy among these studies could in part be attributable to different compliance with the legislation and different changes in smoking behavior among different countries.

Our meta-regression analysis showed that the reduction in acute MI risk was greater in studies with higher smoking prevalence rate decreases, suggesting that the protective effect of legislation could be directly attributed to the

Table 1 Random effects meta-regression analysis of studies examining the effect of smoke-free legislation on acute myocardial infarction

\begin{tabular}{|c|c|c|c|c|}
\hline \multirow[t]{2}{*}{ Variable } & \multicolumn{2}{|c|}{ Univariate model } & \multicolumn{2}{|c|}{ Multivariate model } \\
\hline & Coefficient $(95 \% \mathrm{Cl})$ & $p$ value & Coefficient $(95 \% \mathrm{Cl})$ & $p$ value \\
\hline \multicolumn{5}{|l|}{ Study population } \\
\hline \multicolumn{5}{|l|}{$\geq 500000$} \\
\hline$<500000$ & $0.060(-0.023$ to 0.142$)$ & 0.157 & $0.048(-0.022$ to 0.118$)$ & 0.176 \\
\hline \multicolumn{5}{|l|}{ Study location } \\
\hline \multicolumn{5}{|l|}{ US } \\
\hline Non-US & $0.133(0.057$ to 0.209$)$ & 0.001 & $0.124(0.049$ to 0.199$)$ & 0.001 \\
\hline Publication Year & $-0.018(-0.042$ to 0.006$)$ & 0.134 & $-0.005(-0.028$ to 0.018$)$ & 0.683 \\
\hline Smoking decrease & $-0.028(-0.052$ to- 0.003$)$ & 0.028 & $-0.027(-0.049$ to -0.006$)$ & 0.014 \\
\hline
\end{tabular}




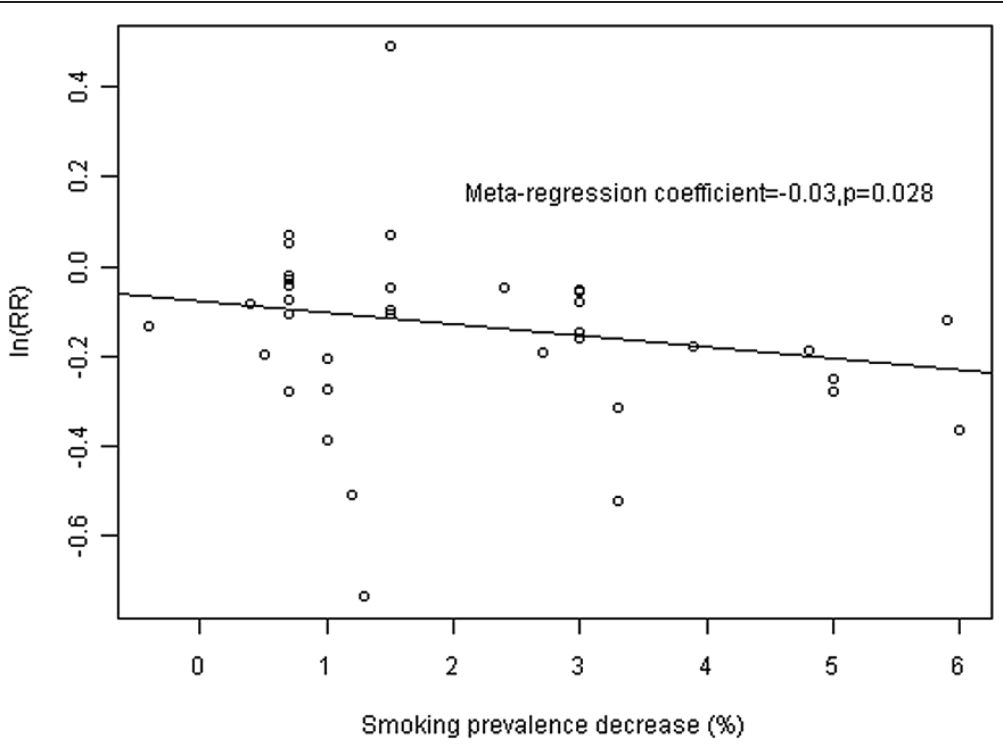

Figure 3 Relationship of AMI decrease with smoking prevalence rate decrease.

corresponding smoking rate decrease. This was corroborated by the study in Arizona, US, which demonstrated a $3.9 \%$ decrease in smoking prevalence, inducing a $13 \%$ reduction of acute MI hospitalization [7].

There were several possible pathways linking the smoking ban regulations to acute MI reduction. The smoking-free policy could reduce the amount of cigarette consumption among the active smokers, encourage smoking quitting, enhance the awareness of the public about the harmfulness of smoking, and more importantly reduce environmental tobacco smoke exposure among the passive smokers. Thus, the beneficial effects could be expected to be in a long-run fashion, besides the short-term effects [37].

The implementation of smoking ban law had been reported to result in significant decline in environmental tobacco smoke [16,38]. For example, in New York, after the implementation of the statewide smoking restriction law, population exposure to environmental tobacco smoke declined by nearly $50 \%$ and cotinine levels in the saliva from New York State adults declined from $0.078 \mathrm{ng} / \mathrm{ml}$ to $0.041 \mathrm{ng} / \mathrm{ml}[11,16]$. In UK and Ireland, a 95\% reduction in ETS among the general population was reported 9 months after the smoking ban [39]. In Scotland, the indoor fine particulate matter $\left(\mathrm{PM}_{2.5}\right)$ concentration declined by $86 \%$ two weeks after the Scottish legislation [38]. In Ireland, salivary cotinine concentration among hotel workers fallen by $69 \%$ and air nicotine concentration dropped by $83 \%$ [40].

This finding strengthened our knowledge that passive smoking was a serious risk factor for acute myocardial infarction and that its elimination reduced the acute MI occurrence $[41,42]$. One percentage decrease in smoking prevalence was estimated to reduce 2.8 percentage of acute MI rate on average. And this association was biologically possible. Exposure to ETS could rapidly induce platelet aggregation, thrombosis, endothelial dysfunction and inflammation, and these effects were comparable to those suffered by active smokers [41,42]. These effects were estimated to increase the risk of acute myocardial infarction by around $10 \%$ globally [43], which was in line with the current estimate. As this risk factor was relatively easily modifiable, the expansion of the smoke-ban policy in public and working places were expected to have a pivotal public health significance.

The strength of the present study included the up to date pooled estimation of the relationship of acute MI risk with the smoke-free legislations and the examination of the correlation of this reduction with the corresponding smoking rate decreases. Meanwhile, a few limitations of this study should be noted. All the included studies were the ecological studies in study design nature, which caused uncertainty in causal inference. Nonetheless, when taken in aggregate, these studies offered evidence that smoking bans were followed by significant reduction in the rate of acute MI in the general population. A recent study reported contradicting results on the impact of smoking ban on acute MI in 387 US counties when adjusting for non-linear secular trend in acute MI compared with the model adjusting for linear secular trend [8]. However, most of the studies included in this meta-analysis did not consider non-linear trend of acute MI rate [44], which might have caused concern in our estimate. Future studies should consider the non-linear secular trend in acute MI occurrence. Temporal trend of acute MI rate might be influenced by factors other than smoking exposure, such as long-term trend, other air pollutants, atmospheric temperature, 
influenza epidemics, changes in diagnostic standards and preventive strategies, which were not taken into account in this meta-analysis. It was also possible that the reduction in acute $\mathrm{MI}$ risk could be due to the reduced amount of cigarettes smoked. It should also be noted that the smoking rate used in the analysis came from diverse sources, where the definition of smoking might be different, however, we used the difference of smoking prevalence before and after the smoking free legislation as the indicator, so this should not have influenced the result seriously.

\section{Conclusion}

The present meta-analysis of 18 individual studies with 44 estimates suggests that smoking bans are associated with significant reduction in AMI occurrence, and that this reduction might be partly due to the declines in smoking prevalence following the smoke-free legislations. Health policy makers, health care professionals should strongly advocate more comprehensive smoking restrictions in public areas and workplaces.

\section{Statement}

The study adheres to the PRISMA guidelines for systematic reviews.

\section{Competing interests}

The authors declare that they have no competing interests.

\section{Authors' contributions}

HLL, QZW and LWT conceived and designed the study; HLL, HCW, LLL and WW performed the analysis and drafted the manuscript. All authors approved the submitted version of the manuscript.

\section{Acknowledgements}

This study was supported by the National Natural Science Foundation of China (NSFC, grant No. 81202176) and the Bloomberg Initiative Grants Program (grant No. CHINA-9-04).

\section{Author details}

${ }^{1}$ Guangdong Provincial Institute of Public Health, Guangzhou, China. ${ }^{2}$ Center for Disease Control and Prevention of Guangdong Province, Guangzhou, Guangdong, China. ${ }^{3}$ Qilu Hospital of Shandong University, Jinan, China. ${ }^{4}$ Department of neurology, Qilu Hospital of Shandong University, Jinan, China. ${ }^{5}$ The Jockey Club School of Public Health and Primary Care, The Chinese University of Hong Kong, Hong Kong, China. 'Shenzhen Municipal Key Laboratory for Health Risk Analysis, Shenzhen Research Institute of the Chinese University of Hong Kong, Shenzhen, China.

Received: 15 January 2013 Accepted: 21 May 2013 Published: 31 May 2013

\section{References}

1. Mackay JM, Eriksen M: The tobacco atlas. Geneva: WHO; 2002.

2. Menke JM, Malone DC: Which Public Policy is More Cost-Effective in Reducing Cardiac Deaths: Increased Taxes or Smoking Bans? 2011. http://www. pharmacy.arizona.edu/sites/default/files/MenkePoster.pdf.

3. Naiman A, Glazier RH, Moineddin R: Association of anti-smoking legislation with rates of hospital admission for cardiovascular and respiratory conditions. CMAJ 2010, 182(8):761-767.
4. U. S. Department of Health \& Human Services: The Health Consequences of Smoking: A Report of the Surgeon General. 2004. http://www.surgeongeneral. gov/library/reports/smokingconsequences/index.html.

5. Lin H, An Q, Luo C, Pun VC, Chan CS, Tian L: Gaseous air pollution and acute myocardial infarction mortality in Hong Kong. A time-stratified case-crossover study. Atmospheric Environment 2012. doi:10.1016/j. atmosenv.2012.08.043

6. Ferrante D, Linetzky B, Virgolini M, Schoj $\vee$, Apelberg B: Reduction in hospital admissions for acute coronary syndrome after the successful implementation of $100 \%$ smoke-free legislation in Argentina: a comparison with partial smoking restrictions. Tobacco Control 2011, 21(4):406-6.

7. Herman PM, Walsh ME: Hospital admissions for acute myocardial infarction, angina, stroke, and asthma after implementation of Arizona's comprehensive statewide smoking ban. Am J Public Health 2011, 101(3):491-499.

8. Barr CD, Diez DM, Wang Y, Dominici F, Samet JM: Comprehensive Smoking Bans and Acute Myocardial Infarction Among Medicare Enrollees in 387 US Counties: 1999-2008. Am J Epidemiol 2012, 176(7):642-648.

9. Mackay DF, Irfan MO, Haw S, Pell JP: Meta-analysis of the effect of comprehensive smoke-free legislation on acute coronary events. Heart 2010, 96(19):1525-1530

10. Bartecchi C, Alsever RN, Nevin-Woods C, Thomas WM, Estacio RO, Bartelson $B B$, Krantz MJ: Reduction in the incidence of acute myocardial infarction associated with a citywide smoking ordinance. Circulation 2006, 114(14):1490-1496.

11. Alsever RN, Thomas WM, Nevin-Woods C, Dennison S, Bueno R, Chang L, Bartecchi CE, Babb S, Trosclair A, Engstrom M, Pechacek T, Kaufmann R: Reduced hospitalizations for acute myocardial infarction after implementation of a smoke-free ordinance--City of Pueblo, Colorado, 2002-2006. MMWR. Morbidity and mortality weekly report 2009, 57\%6(51):1373-1377.

12. Trachsel LD, Kuhn MU, Reinhart WH, Schulzki T, Bonetti PO: Reduced incidence of acute myocardial infarction in the first year after implementation of a public smoking ban in Graubuenden, Switzerland. Swiss Med Wkly 2010, 140(9-10):133-138.

13. Bonetti PO, Trachsel LD, Kuhn MU, Schulzki T, Erne P, Radovanovic D, Reinhart WH: Incidence of acute myocardial infarction after implementation of a public smoking ban in Graubünden, Switzerland: Two year follow-up. Swiss Med Wkly 2011, 141:w13206.

14. Vasselli S, Papini P, Gaelone D, Spizzichino L, Campora ED, Gnavi R, Saitto C, Binkin N, Laurendi G: Reduction incidence of myocardial infarction associated with a national legislative ban on smoking. Minerva Cardioangiol 2008, 56(2):197-203.

15. Barone-Adesi F, Vizzini L, Merletti F, Richiardi L: Short-term effects of Italian smoking regulation on rates of hospital admission for acute myocardial infarction. Eur Heart J 2006, 27(20):2468-2472.

16. Juster HR, Loomis BR, Hinman TM, Farrelly MC, Hyland A, Bauer UE, Birkhead GS: Declines in Hospital Admissions for Acute Myocardial Infarction in New York State After Implementation of a Comprehensive Smoking Ban. Am J Public Health 2007, 97(11):2035-2039.

17. Rodu B, Peiper N, Cole P: Acute Myocardial Infarction Mortality Before and After State-wide Smoking Bans. J Community Health 2012, 37(2):468-472.

18. American Lung Association: Trends in Tobacco Use. 2011. http://www.lung. org/finding-cures/our-research/trend-reports/Tobacco-Trend-Report.pdf.

19. Yaffe B: Toronto's Health Status. Toronto, Canada: Focus on Tobacco. City of Toronto; 2004. http://www.toronto.ca/health/hsi/pdf/hsi_tobacco_profile.pdf.

20. UK Cancer Research: Smoking statistics in UK. 2011. http://info.cancerresearchuk org/cancerstats/types/lung/smoking/.

21. Gallus S, Zuccaro P, Colombo P, Apolone G, Pacifici R, Garattini S, Bosetti C, La Vecchia C: Smoking in Italy 2005-2006: Effects of a comprehensive National Tobacco Regulation. Prev Med 2007, 45(2-3):198-201.

22. Laugesen M: Has smoking prevalence markedly decreased in New Zealand despite more cigarettes released for sale? J of the New Zealand Med Ass 2009, 122(1290):76-82.

23. Swiss start to cut back smoking habit. 2010. http://www.swissinfo.ch/eng/ swiss_news/Swiss_start_to_cut_back_smoking_habit.html?cid=9037970.

24. Marques-Vidal P, Cerveira J, Paccaud F, Cornuz J: Smoking trends in Switzerland, 1992-2007: a time for optimism? J Epidemiol Community Health 2009, 65(3):281-286.

25. Dove MS, Dockery DW, Mittleman MA, Schwartz J, Sullivan EM, Keithly L, Land T: The Impact of Massachusetts' Smoke-Free Workplace Laws on Acute Myocardial Infarction Deaths. Am J Public Health 2010, 100(11):2206-2212. 
26. McAlister AL, Huang P, Ramirez AG, Harrist RB, Fonseca VP: Reductions in Cigarette Smoking and Acute Myocardial Infarction Mortality in Jefferson County, Texas. Am J Public Health 2010, 100(12):2391-2392.

27. Seo DC, Torabi MR: Reduced admissions for acute myocardial infarction associated with a public smoking ban: matched controlled study. J Drug Educ 2007, 37(3):217-226.

28. Sargent RP, Shepard RM, Glantz SA: Reduced incidence of admissions for myocardial infarction associated with public smoking ban: before and after study. BMJ 2004, 328(7446):977-980.

29. Lemstra M, Neudorf C, Opondo J: Implications of a public smoking ban. Can J Public Health 2008, 99(1):62-65.

30. Glantz SA: Meta-analysis of the effects of smokefree laws on acute myocardial infarction: an update. Prev Med 2008, 47(4):452-454.

31. Meyers DG, Neuberger JS, He J: Cardiovascular Effect of Bans on Smoking in Public Places: A Systematic Review and Meta-Analysis. J Am Coll Cardiol 2009, 54(14):1249-1255.

32. Dinno A, Glantz S: Clean indoor air laws immediately reduce heart attacks. Prev Med 2007, 45(1):9-11.

33. Lightwood JM, Glantz SA: Declines in acute myocardial infarction after smoke-free laws and individual risk attributable to secondhand smoke. Circulation 2009, 120:1373-1379.

34. Pechacek TF, Babb S: How acute and reversible are the cardiovascular risks of secondhand smoke? BMJ 2004, 328(7446):980-983.

35. Khuder SA, Milz S, Jordan T, Price J, Silvestri K, Butler P: The impact of a smoking ban on hospital admissions for coronary heart disease. Prev Med 2007, 45(1):3-8.

36. Barnett R, Pearce J, Moon G, Elliott J, Barnett P: Assessing the effects of the introduction of the New Zealand Smokefree Environment Act 2003 on Acute Myocardial Infarction hospital admissions in Christchurch, New Zealand. Aust N Z J Public Health 2009, 33(6):515-520.

37. Hurt RD, Weston SA, Ebbert JO, McNallan SM, Croghan IT, Schroeder DR, Roger VL: Myocardial Infarction and Sudden Cardiac Death in Olmsted County, Minnesota, Before and After Smoke-Free Workplace LawsMI and Cardiac Death With Smoke-Free Workplace Law. Arch Intern Med 2012 172(21):1635-1641.

38. Semple S, Creely KS, Naji A, Miller BG, Ayres JG: Secondhand smoke levels in Scottish pubs: the effect of smoke-free legislation. Tob Control 2007 16(2):127-132

39. Fong GT, Hyland A, Borland R, Hammond D, Hastings G, McNeill A, Anderson S, Cummings K, Allwright S, Mulcahy M: Reductions in tobacco smoke pollution and increases in support for smoke-free public places following the implementation of comprehensive smoke-free workplace legislation in the Republic of Ireland: findings from the ITC Ireland/UK Survey. Tob Control 2006, 15(suppl 3):iii51.

40. Mulcahy M, Byrne $M$, Ruprecht $A$ : How does the Irish smoking ban measure up? A before and after study of particle concentrations in Irish pubs. Small 2005, 1(2):3-4.

41. Glantz SA, Parmley WW: Passive smoking and heart disease. Mechanisms and risk. JAMA 1995, 273(13):1047-1053.

42. Glantz SA, Parmley WW: Even a little secondhand smoke is dangerous. JAMA 2001, 286(4):462.

43. Pope CA: Acute exposure to environmental tobacco smoke and heart rate variability. Environ Health Perspect 2001, 109(7):711-716.

44. Sims M, Maxwell R, Bauld L, Gilmore A: Short term impact of smoke-free legislation in England: retrospective analysis of hospital admissions for myocardial infarction. BMJ 2010, 340:C2161.

\section{Submit your next manuscript to BioMed Central and take full advantage of:}

- Convenient online submission

- Thorough peer review

- No space constraints or color figure charges

- Immediate publication on acceptance

- Inclusion in PubMed, CAS, Scopus and Google Scholar

- Research which is freely available for redistribution

Submit your manuscript at www.biomedcentral.com/submit
C Biomed Central 